Research article

Original articles

https://doi.org/10.17308/kcmf.2021.23/3676

\title{
Synthesis of chitosan and $N$-vinylimidazole graft-copolymers and the properties of their aqueous solutions
}

\author{
A. V. Sorokin ${ }^{1,2}$, M. G. Kholyavka ${ }^{1,3}$, M. S. Lavlinskaya ${ }^{2 凶}$ \\ ${ }^{1}$ Voronezh State University, \\ 1 Universitetskaya pl., Voronezh 394018, Russian Federation \\ ${ }^{2}$ Voronezh State University of Engineering Technologies, \\ 19 Prospekt Revolutsii, 394036 Voronezh, Russian Federation \\ ${ }^{3}$ Sevastopol State University \\ 33 Universitetskaya ul., Sevastopol 299053, Russian Federation
}

\begin{abstract}
The aim of this work is to synthesise chitosan and $N$-vinylimidazole graft-copolymers of various compositions and to study the properties of their aqueous solutions.

Chitosan and N-vinylimidazole graft-copolymers were obtained by solution polymerisation in the presence of a ceric ammonium nitrate redox initiator. The synthesised graft copolymers were characterised by FTIR to determine their compositions and the grafted side chains of poly- $N$-vinylimidazole were characterised by gel permeation chromatography to determine their molecular wights and polydispersity indices. It was established that the obtained products are characterised by high values of yield and grafting efficiency and low values of the polydispersity index. It was found that when the content of the $N$-vinylimidazole links is above $57 \mathrm{wt} \%$, the synthesised graft copolymers are water-soluble. Aqueous solutions of the obtained copolymers were characterised using dynamic light scattering, transmission electron microscopy, and laser Doppler microelectrophoresis. The study showed that macromolecules of graft copolymers in aqueous solutions have stimuli-sensitive properties with respect to the medium reaction and at a concentration above $10^{-2}$ wt\% are characterised by a tendency to self-association forming core-crown aggregates, the geometry of which depends on the molecular masses of the grafted chains. Associates of macromolecules in solutions are characterised by positive values of the electrokinetic potential, the values of which also depend on the medium reaction. Thus, it was found that the ceric ammonium nitrate initiator allows obtaining chitosan and $N$-vinylimidazole graft-copolymers showing stimuli-sensitive properties in aqueous solutions and prone to self-association at concentrations above $10^{-2} \mathrm{wt} \%$.
\end{abstract}

Keywords: Graft copolymers, Aqueous solutions of polymers, Stimuli sensitivity, chitosan, $N$-vinylimidazole

Acknowledgements: the reported study was supported by the Russian Science Foundation, project No. 21-74-20053. IR spectroscopy, transmission electron microscopy, dynamic light scattering, and laser Doppler microelectrophoresis data were obtained using the equipment of the Centre for Collective Use of Scientific Equipment of Voronezh State University.

For citation: Sorokin A. V., Kholyavka M. G., Lavlinskaya M. S. Synthesis of chitosan and $N$-vinylimidazole graft-copolymers and the properties of their aqueous solutions. Kondensirovannye sredy $i$ mezhfaznye granitsy = Condensed Matter and Interphases. 2021;23(4): 570-577. https://doi.org/10.17308/kcmf.2021.23/3676

Для цитирования: Сорокин А. В., Холявка М. Г., Лавлинская М. С. Синтез и свойства водных растворов графтсополимеров хитозана и N-винилимидазола. Конденсированные среды и межфазные границы. 2021;23(4): 570-577. https://doi.org/10.17308/kcmf.2021.23/3676

Maria S. Lavlinskaya, e-mail: maria.lavlinskaya@gmail.com (c) A. V. Sorokin, M. G. Kholyavka, M. S. Lavlinskaya, 2021 


\section{Introduction}

Currently, more and more research are being focused on polymeric materials of natural origin. One of the most popular materials of that kind is chitosan. This poly- $\beta$-glycoside is a linear copolymer of $D$-glucosamine and $N$-acetyl$D$-glucosamine binded by $1,4-\beta$-glycosidic linkages [1]. Chitosan is obtained by alkaline deacetylation of chitin, a natural polysaccharide that forms the shells of crustaceans and insects. It is also present in fungi bodies [2]. Due to the widespread renewable sources of raw materials for the production of chitosan, it is the second most common biopolymer, which has a number of properties of practical significance. They include low toxicity, biocompatibility, and intrinsic biological activity, which allow using chitosan for biomedical purposes [1,3]. For example, some sources provide extensive information on the use of chitosan-based macromolecules of various architecture as a carrier of biologically active substances and medicinal products for oral [4] and transdermal delivery [5]. It can also be used to create innovative dressing and wound covering materials [6-7], in tissue engineering [8-9], etc.

Like many materials of natural origin, chitosan has a number of features that make it difficult to work with it. The properties of polymers are largely determined by their molecular weight (MW). Therefore, chitosan with a MW over 20,000 is insoluble in water, and at higher values of MW, it is characterised by the ability to dissolve in aqueous solutions of monohydric acids due to protonation of the free amino group of glucosamine links $[1,3]$. These factors can limit the possibilities of using chitosan. In this regard, it is advisable to modify its macromolecules by expanding the $\mathrm{pH}$ range of polymer dissolution in aqueous media.

One of the most promising forms of the polysaccharide modification is graft copolymerisation, which does not require strict conditions or expensive reagents [10-11]. By varying the frequency of side chain grafting in the resulting graft copolymers, it is possible to change the conformation of their polymer macromolecules in aqueous solutions. Thus, it is possible to form hard macromolecular brushes or soft statistical coils, as well as to change the ability of macromolecules to form conjugates with various low and high molecular weight compounds [12-13]. In addition, the introduction of side chains with functional substituents also increases the ability of graft copolymers to interact with various substances [14-15].

A promising comonomer for the preparation of chitosan graft copolymers is $N$-vinylimidazole. The azole cycle in its composition is characterised by a high complex-forming potential due to its ability be involved in acid-base and stacking interactions, as well as to form hydrogen bonds [16]. Moreover, its homopolymer, poly- $N$ vinylimidazole, is water-soluble in a wide range of concentrations and has its own physiological activity: it can act as a catalyst, and, like chitosan, is antibacterially active [17-19]. The combination of these properties suggests that chitosan and $N$-vinylimidazole graft copolymers will be promising materials for, for example, biomedical applications.

Therefore, the aim of this work is to synthesise chitosan and $N$-vinylimidazole graft-copolymers of various compositions and to study the properties of their aqueous solutions.

\section{Experimental}

We used chitosan (Cht) with a molecular mass of $600 \times 10^{3}$ and the degree of deacetylation of 0.85 ; a commercial monomer $N$-vinylimidazole (VI), all of them produced by Sigma Aldrich, Germany. The polymer was used without additional purification, the monomer was distilled in vacuum immediately before use $\left(T_{b p}=78-79^{\circ} \mathrm{C} / 11 \mathrm{mmHg} ; n_{D}^{20}=1.5338\right)$. Ceric ammonium nitrate (CAN) (Acros Organics, USA) was used without additional purification as the initiator of the radical process.

Graft copolymers were prepared by solution polymerisation with redox initiation use. A weighed portion of chitosan $(0.5 \mathrm{~g})$ was placed in $100 \mathrm{ml}$ of a $2 \%$ acetic acid solution and kept at room temperature until the polysaccharide was completely dissolved. Then, the calculated amount of monomer and initiator was added to the mixture (Table 1) and the mixture was left at a temperature of $25 \pm 2{ }^{\circ} \mathrm{C}$ for 8 hours. The resulting graft copolymer was isolated by precipitation in acetone, after which it was dissolved in water, filtered off, the filtrate was dialysed against distilled water through a cellophane membrane 


\section{A. V. Sorokin et al.}

Таблица 1. Условия синтеза графт-сополимеров

\begin{tabular}{|c|c|c|c|c|c}
\hline No & Cht, g & $\begin{array}{c}2 \% \\
\mathrm{CH}_{3} \mathrm{COOH}, \\
\mathrm{ml}\end{array}$ & VI, ml & CAN, g & $\begin{array}{c}\text { Yield, } \\
\%\end{array}$ \\
\hline 1 & 0.5 & 100 & 0.1 & 0.06 & 52 \\
\hline 2 & 0.5 & 100 & 0.5 & 0.10 & 61 \\
\hline 3 & 0.5 & 100 & 1.0 & 0.15 & 69 \\
\hline 4 & 0.5 & 100 & 1.5 & 0.20 & 76 \\
\hline
\end{tabular}

with a pore size of $12 \mathrm{kDa}$ for 7 days, after which it was freeze-dried to a constant weight. The product yield was $52-76 \%$.

The molecular weights of the grafted side chains and the polydispersity index (PDI) were determined by gel permeation chromatography according to the method described in [14].

The grafting efficiency (GE) was calculated using the following formula [14]:

$G E=\frac{m_{2}-m_{1}}{m_{1}} \cdot 100$

where $m_{1}$ and $m_{2}$ are the respective masses of the original chitosan and the purified dried graft copolymer in grams.

The compositions of the obtained copolymers were determined by FTIR. The spectra were recorded by a Bruker Vertex 70 instrument (Bruker Optics, Germany) by a FTIR ATR method in the frequency range of $500-4000 \mathrm{~cm}^{-1}$. The composition was calculated from the ratio of the areas of absorption bands at 1591 and $1420 \mathrm{~cm}^{-1}$ related to the vibrations of the primary chitosan amino group and the $-\mathrm{C}=\mathrm{N}-$ bond of the azole cycle, respectively.

The properties of aqueous solutions of the synthesised graft copolymers with various concentrations of the synthesised graft copolymers were studied by the method of dynamic light scattering using a Malvern ZetaSizer Nano apparatus (Malvern Instruments, Great Britain) equipped with a He-Ne laser with a power of $25 \mathrm{~mW}$ and a wavelength of $\lambda=632.8 \mathrm{~nm}$. The data were recorded at an angle of $90^{\circ}$ at 25 ${ }^{\circ} \mathrm{C}$ in cuvettes equipped with a gold electrode, the measurement cycle time was 120 seconds, the number of cycles was between 3-6 and was determined automatically.

The particle shape of graft copolymers in aqueous solutions was determined by transmission electron microscopy using a Libra
120 apparatus (Carl Zeiss, Germany). Before recording, the polymer solution was applied dropwise onto a formvar-coated copper plate and dried in an air stream.

\section{Results and discussion}

Chitosan graft copolymers with different contents of $\mathrm{N}$-vinylimidazole were obtained by solution radical polymerisation with redox initiation using ceric ammonium nitrate. It is well known that depending on the synthesis conditions it is possible to obtain copolymers of polysaccharides with different architectures. The most important factors influencing the structure of the formed macromolecules are the temperature and the nature of the initiator. In thermal conditions above $50{ }^{\circ} \mathrm{C}$ and in the presence of initiators characterised by high values of redox potentials, there are primarily reactions of the formation of block copolymers of polyglycosides or homopolymers of the used comonomers [10]. Therefore, to obtain the graftcopolymer architecture, the synthesis was carried out at room temperature in the presence of ceric ammonium nitrate, the transition potential of which $\mathrm{Ce}^{+4} / \mathrm{Ce}^{+3}$ was lower than commonly used persulphates or permanganates.

The mechanism of the reaction for the formation of the graft copolymer can be represented as follows (Scheme 1): the cerium (IV) ion interacts with the amino or hydroxyl groups of chitosan forming a complex compound. This results in the removal of a hydrogen atom from the pyranose cycle substituent, the formation of radicals on oxygen or nitrogen atoms, and the reduction of cerium to the Ce (III) state. The radicals formed on the polyglycoside chain interact with the monomers forming a new macroradical. Subsequent similar interactions lead to the chain growth. The chain termination is possible due to the recombination with another active centre or through reactions of chain transfer to other components [15].

The structure of the resulting products was confirmed using FTIR (Fig. 1). The chitosan IR spectrum contains the following characteristic absorption bands: $1024-1150 \mathrm{~cm}^{-1}$ related to skeletal vibrations of the pyranose cycle and the C-O-C fragment, a series of bands at 1262 , 1320,1375 , and $2870 \mathrm{~cm}^{-1}$ corresponding to 


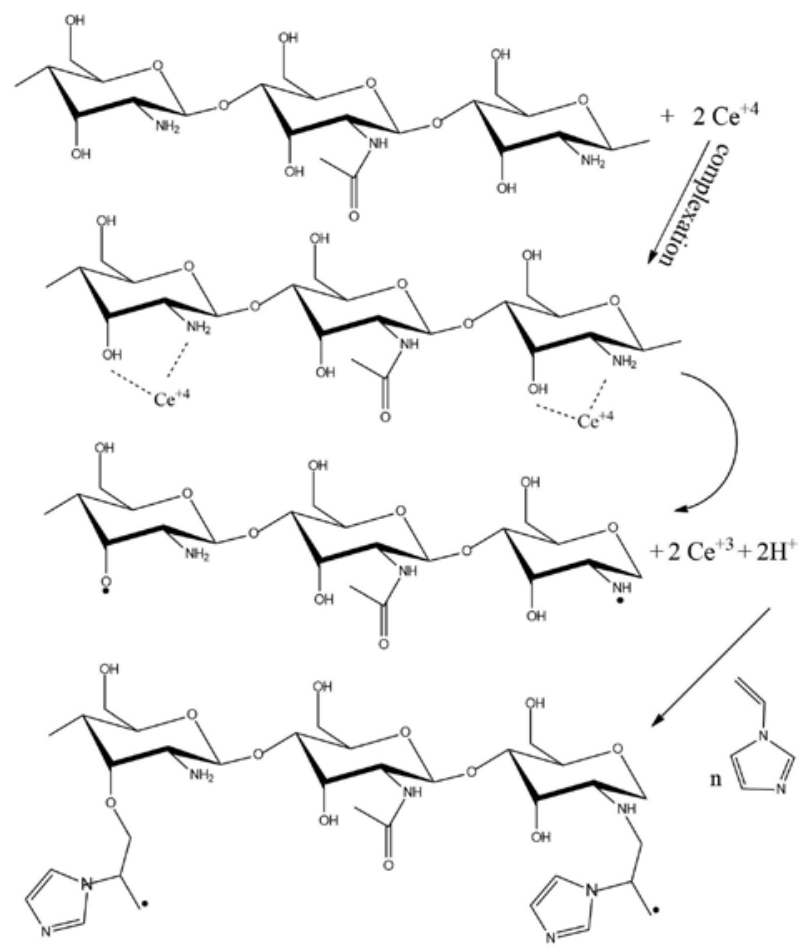

Scheme 1. Possible mechanism for the graft copolymer formation

deformation vibrations of methyl and methylene groups of the polysaccharide cyclic fragment, at $1647 \mathrm{~cm}^{-1}$, stretching vibrations of the $\mathrm{C}=0$ group of $N$-acetyl- $D$-glucosamine residues, at $1591 \mathrm{~cm}^{-1}$ vibrations of the primary amino group; and a broad absorption band at $3357 \mathrm{~cm}^{-1}$ related to the vibrations of $\mathrm{OH}$ groups of water molecules associated with polymer macromolecules [20]. The IR spectrum of the graft copolymer contains the above-mentioned bands, and in addition, new ones appear at $2914 \mathrm{~cm}^{-1}$ corresponding to the vibrations of the azole cycle and a band at $1420 \mathrm{~cm}^{-1}$ corresponding to the vibrations of the $-\mathrm{C}=\mathrm{N}-$ bond of the side substituent of the grafted poly- $N$-vinylimidazole chain.

The most important factor determining the properties of a macromolecule of any structure is its molecular weight. It is assumed that during

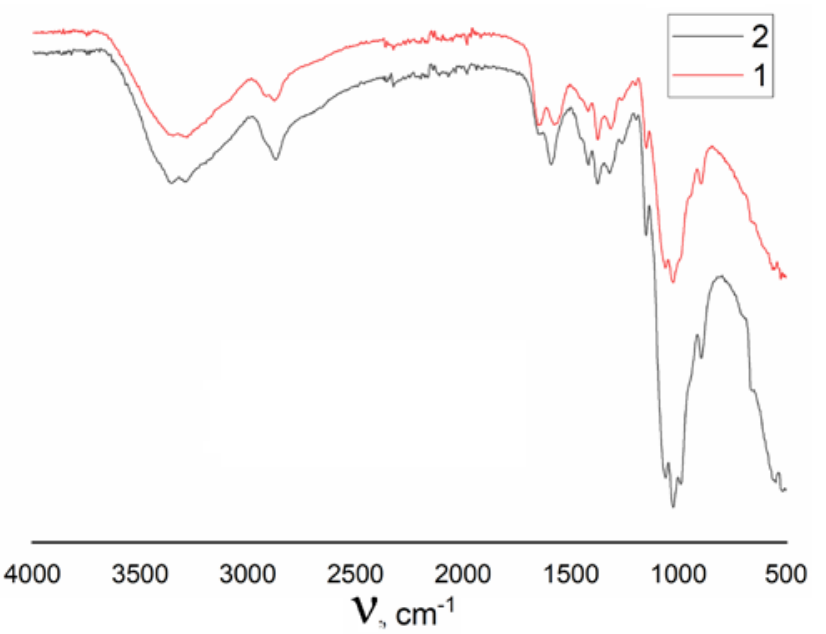

Fig. 1. FTIR spectra: (1) chitosan, (2) chitosan with $\mathrm{N}$-vinylimidazole graft copolymer

the reaction of the graft copolymer formation, the molecular weight of the original chitosan does not change. Therefore, we studied the side chains of poly- $N$-vinylimidazole (PVI) isolated as a result of acid destruction of the polyglycoside chains. The results of the molecular weights are presented in Table 2. As expected, with an increase in the monomer content in the initial polymerisation mixture, there is an increase in the molecular weights of the grafted chains. However, under the same conditions, there is an insignificant decrease in the value of the grafting efficiency. This is due to an increase in the total viscosity of the reaction mixture and, as a consequence, an increase in the number of side processes, including the VI homopolymerisation. Separately, it is worth discussing the values of the polydispersity index (PDI) of side chains obtained as a result of the study: they are low enough for a free-radical process, which also indicates that the initiator for the synthesis of graft copolymers was well-chosen.

The compositions of the obtained copolymers calculated using the FTIR data are given in Table 2. As can be seen from the presented values,

Table 2. Characteristics of the synthesised graft copolymers

\begin{tabular}{|c|c|c|c|c|c|c|c|c|c|}
\hline \multirow{2}{*}{ No } & \multirow{2}{*}{$\begin{array}{c}\text { PVI content, } \\
\text { wt } \%\end{array}$} & \multirow{2}{*}{ GE, \% } & \multicolumn{3}{|c|}{ PVI grafted chains } & \multirow{2}{*}{$\begin{array}{l}\text { Water- } \\
\text { solubility }\end{array}$} & \multirow{2}{*}{$\begin{array}{l}D_{h}{ }^{1}, \\
\mathrm{~nm}\end{array}$} & \multirow{2}{*}{$\begin{array}{l}\zeta^{1}, \\
\mathrm{mV}\end{array}$} & \multirow{2}{*}{$\begin{array}{r}c^{*}, \\
\text { wt\% }\end{array}$} \\
\hline & & & $M_{W}$ & $M_{N}$ & PDI & & & & \\
\hline 1 & 17 & 68 & 7269 & 5679 & 1.28 & - & - & - & - \\
\hline 2 & 42 & 56 & 16835 & 12754 & 1.32 & - & - & - & - \\
\hline 3 & 57 & 49 & 19907 & 15432 & 1.29 & + & 139 & 17.3 & 0.02 \\
\hline 4 & 74 & 42 & 22064 & 16843 & 1.31 & + & 158 & 20.1 & 0.03 \\
\hline
\end{tabular}


with an increase in the $N$-vinylimidazole content in the polymerisation mixture the number of its links in the final copolymer increases. Poly$N$-vinylimidazole, unlike chitosan, is a watersoluble polymer. Therefore, it is the number of PVI links in the macromolecules that determines the copolymer's ability to dissolve in water. It was found that samples containing less than 57 wt\% of PVI are insoluble in water, however, they dissolve in acidic solutions with a $\mathrm{pH}<6.5$. Further research was only conducted with watersoluble copolymers.

The dynamic light scattering(DLS) method was used to determine the values of the hydrodynamic diameters, $D_{\mathrm{h}}$, and particles of copolymers in $1 \%$ aqueous solutions. It was found that the systems under consideration are characterised by a narrow unimodal distribution of particles by sizes with the values of $D_{\mathrm{h}}$ within the range of $139-158 \mathrm{~nm}$ (Table 2). Using these values, it can be concluded that the particles of the synthesised graft copolymers in aqueous solutions are aggregates of several macromolecular chains.

Previous studies show that aggregates of polysaccharide macromolecules in aqueous solutions can have a geometry other than spherical [14]. In this case, it might be incorrect to use the method of dynamic light scattering to determine the size of such particles. Therefore, to study solutions of graft copolymers, we also used the method of transmission electron microscopy (TEM) (Fig. 2). The values of the particle sizes in the solution obtained by various methods correlate with each other. However, it should be noted that with a change in the molecular weights of the grafted PVI chains, the geometry of the multichain aggregate also changes: with an increase in the molecular mass and the percentage of the grafted PVI chains, the shape of the aggregates changes and becomes less elongated and oval (which is more characteristic of polysaccharides) and becomes spherical. Moreover, the aggregates of both types have a pronounced structure with a dense core surrounded by a looser crown.

Given the tendency of macromolecules of water-soluble polysaccharides and poly$\mathrm{N}$-vinylimidazole to self-aggregation, it is of interest to determine the critical overlap coil concentration (COCC), $c^{*}$, in water. For this, the dynamic light scattering method was used to determine the hydrodynamic diameters of particles in the concentration range of $10^{-4}$ $0.5 \mathrm{wt} \%$. The results of the study are shown in Fig. 3. As can be seen from the obtained data (Table 2), the COCC values increase with a growth in the molecular weights of the final modified polysaccharide, which is consistent with previously published data [21].

Another important characteristic for polymer solutions is the surface charge of particles, which is determined by the electrokinetic potential $(\zeta)$. To determine it, the laser Doppler microelectrophoresis method was used. All synthesised water-soluble graft copolymers are characterised by a positive value of the electrokinetic potential, which is due to the influence of nitrogen atoms of the side substituents of both the polysaccharide and the grafted side chains. It should be noted that with an increase in the molecular weight of the

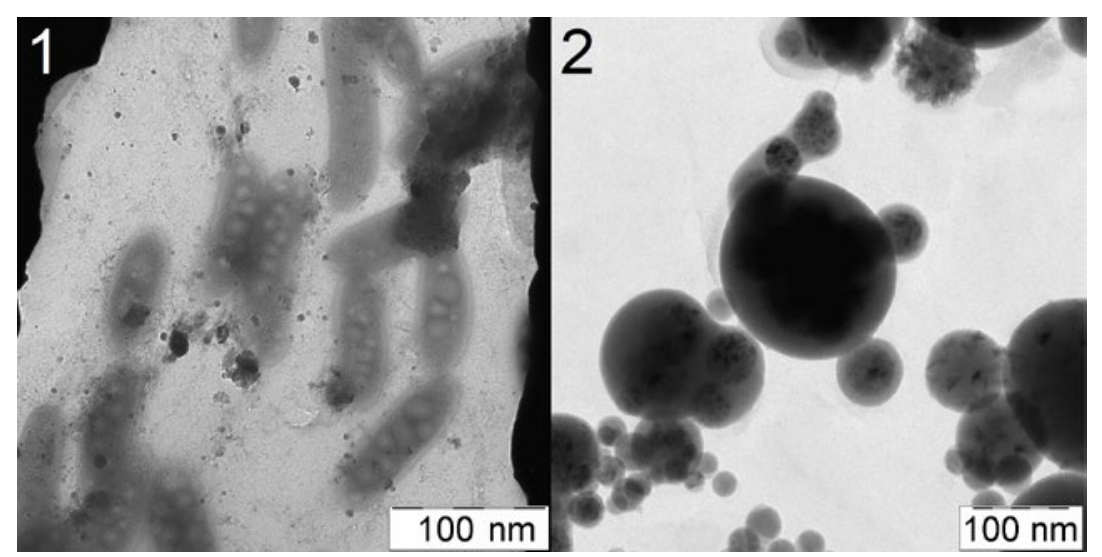

Fig. 2. TEM images of copolymer particles: (1) copolymer containing $17 \mathrm{wt} \%$ of VI; (2) copolymer containing $57 \mathrm{wt} \%$ of VI 


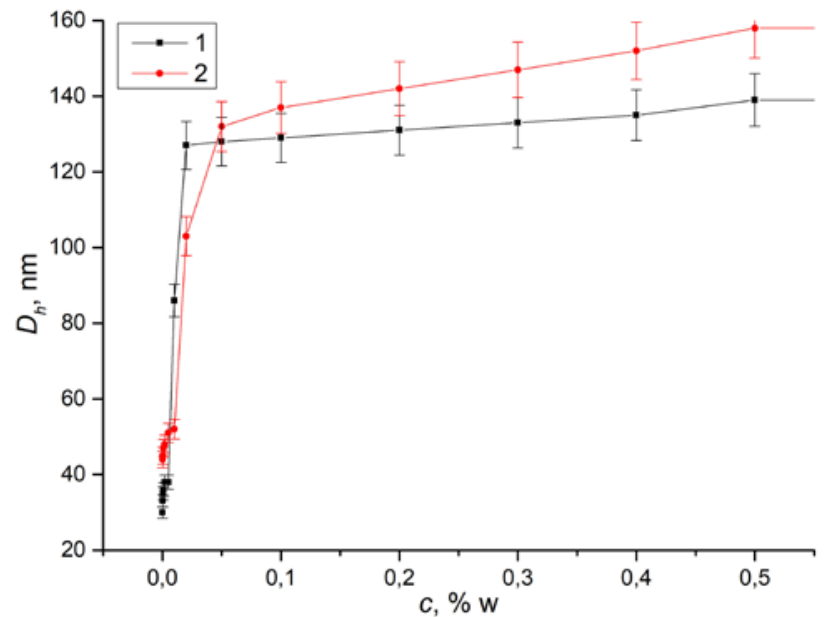

Fig. 3. Dependences of the particle sizes of the copolymer in solution on their concentration: (1) copolymer containing 57 wt\% of VI; (2) copolymer containing $74 \mathrm{wt} \%$ of VI

grafted chains and the percentage of azole links in the macromolecules of graft copolymers, the value of the electrokinetic potential increases insignificantly.

It is well known that azole cycles are capable of acid-base interactions. Therefore, their introduction into macromolecules can make them stimuli-sensitive. We studied the dependence of the particle size on the medium reaction for a copolymer containing $57 \mathrm{wt} \%$ of PVI units at a concentration below the COCC, $10^{-3}$ wt\% (Fig. 4). It was found that with an increase in the $\mathrm{pH}$ value, the values of the hydrodynamic diameter of the particles decrease in the range at $\mathrm{pH}<8$, after which their size remains practically unchanged. The study of the dependence of the change in the values of the electrokinetic potential from the $\mathrm{pH}$ value showed the following: at $\mathrm{pH}<7$, the particles of graft copolymers are characterised by positive values of the zeta potential, and with an increase in $\mathrm{pH}$ values, the particles lose their charge. Thus, the synthesised graft copolymers are stimuli-sensitive macromolecules that change their sizes and charges depending on external conditions.

\section{Conclusion}

Thus, we successfully synthesised chitosan and $\mathrm{N}$-vinylimidazole graft copolymers with relatively high values of yields and grafting efficiency. The content of azole links above $57 \mathrm{wt} \%$ ensures the water solubility of polymers. Depending on the

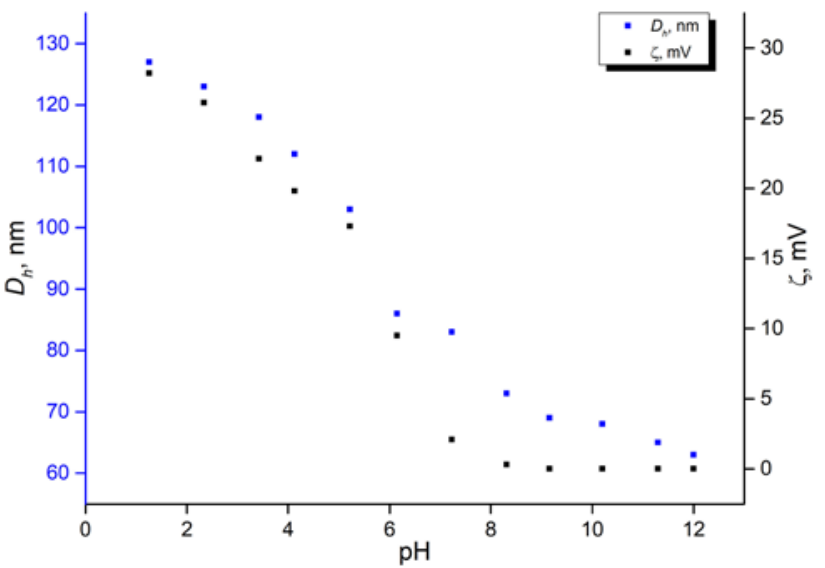

Fig. 4. Dependences of the particle size of the copolymer and the electrokinetic potential on the medium reaction

concentration of graft copolymers, the particles of copolymers in solutions can be both in the form of single coils or multi-chain aggregates, the geometry of which depends on the grafting efficiency. It was found that regardless of the form of macromolecules in the solution, they are characterised by positive values of electrokinetic potential. However, with a change in $\mathrm{pH}$, graft copolymers can change the size and charge of the particles in the solution. Thus, the obtained stimuli-sensitive polymers may be of interest for biomedical applications.

\section{Conflict of interests}

The authors declare that they have no known competing financial interests or personal relationships that could have influenced the work reported in this paper.

\section{Author contributions}

All authors made an equivalent contribution to the preparation of the publication.

\section{References}

1. Jayakumar R., Prabaharan M., Muzzarelli R.(Eds.). Chitosan for biomaterials I. In: Advances in Polymer Science. Berlin - Heidelberg: Springer-Verlag; 2011. 236 p. https://doi.org/10.1007/978-3-642-23114-8

2. Kou S., Peters L. M., Mucalo M. R. Chitosan: A review of sources and preparation methods. International Journal of Biological Macromolecules. 2021;169: 85-94. https://doi.org/10.1016/j. ijbiomac.2020.12.005 
3. Jennings J. A., Bumgardner J. B. (Eds.). Woodhead Publishing Series in Biomaterials. In: Chitosan based biomaterials. Volume 1: Fundamentals. Duxford; 2017. 325 p. https://doi.org/10.1016/b978-0-08-1002308.09002-6

4. Lang X., Wang T., Sun M., Chen X., Liu Y. Advances and applications of chitosan-based nanomaterials as oral delivery carriers: A review. International Journal of Biological Macromolecules. 2020;154: 433-445. https://doi.org/10.1016/j. ijbiomac.2020.03.148

5. Sivasankarapillai V. S., Das S. S., Sabir F., Sundaramahalingam M. A., Colmenares J. C., Prasannakumar S., Rajan M., Rahdar A., Kyzas G. Z. Progress in natural polymer engineered biomaterials for transdermal drug delivery systems. Materials Today Chemistry. 2021;19:100382. https://doi.org/10.1016/j. mtchem.2020.100382

6. Ueno H., Mori T., Fujinaga T. Topical formulations and wound healing applications of chitosan. Advanced Drug Delivery Reviews. 2001;52(2): 105-115. https:// doi.org/10.1016/S0169-409X(01)00189-2

7. Patrulea V., Ostafe V., Borchard G., Jordan O. Chitosan as a starting material for wound healing applications. European Journal of Pharmaceutics and Biopharmaceutics, Part B. 2015;97: 417-426. https:// doi.org/10.1016/j.ejpb.2015.08.004

8. Pita-López M. L., Fletes-Vargas G., EspinosaAndrews H., Rodríguez-Rodríguez R. Physically crosslinked chitosan-based hydrogels for tissue engineering applications: A state-of-the-art review. European Polymer Journal. 2021;45: 110176. https://doi. org/10.1016/j.eurpolymj.2020.110176

9. Madni A., Kousar R., Naeem N., Wahid F. Recent advancements in applications of chitosan-based biomaterials for skin tissue engineering. Journal of Bioresources and Bioproducts. 2021;6(1): 11-25. https://doi.org/10.1016/j.jobab.2021.01.002

10. Berlin Ad. A., Kislenko V. N. Kinetics and mechanism of radical graft polymerization of monomers onto polysaccharides. Progress in Polymer Science. 1992;17(5): 765-825. https://doi. org/10.1016/0079-6700(92)90010-V

11. Sanchez-Salvador J. L., Balea A., Monte M. C., Negro C., Blanco A. Chitosan grafted/cross-linked with biodegradable polymers: A review. International Journal of Biological Macromolecules. 2021;178: 325343. https://doi.org/10.1016/j.ijbiomac.2021.02.200

12. Lee H., Pietrasik J., Sheiko S. S., Matyjaszewski K. Stimuli-responsive molecular brushes. Progress in Polymer Science. 2010;35 (1-2): 24-44. https://doi. org/10.1016/j.progpolymsci.2009.11.002

13. Yan J., Bockstaller M. R., Matyjaszewski K. Brush-modified materials: Control of molecular architecture, assembly behavior, properties and applications. Progress in Polymer Science. 2020;100: 101180. https://doi.org/10.1016/j.progpolymsci.2019.101180

14. Kuznetsov V. A., Sorokin A. V., Lavlinskaya M. S., Sinelnikov A. A., Bykovskiy D. V. Graft copolymers of carboxymethyl cellulose with $\mathrm{N}$-vinylimidazole: synthesis and application for drug delivery. Polymer Bulletin. 2019;76:4929-4949.https://doi.org/10.1007/ s00289-018-2635-0

15. Sorokin A. V., Kuznetsov V. A., Lavlinskaya M. S. Synthesis of graft copolymers of carboxymethyl cellulose and N,N-dimethylaminoethyl methacrylate and their study as Paclitaxel carriers. Polymer Bulletin. 2021;78: 2975-2992. https://doi.org/10.1007/s00289020-03250-z

16. Broekema R. J. Durville P. F. M., Reedijk J., Smit J.A. The coordination chemistry of N-vinylimidazole. Transition Metal Chemistry. 1982;7: 25-28. https://doi. org/10.1007/BF00623803

17. Kodama H., Miyajima T., Tabuchi H. A calorimetric study of the acid dissociation of the conjugate acids of poly(N-vinylimidazole) and polyallylamine. Colloid and Polymer Science. 2000;278: 1-7. https://doi.org/10.1007/s003960050001

18. Na C. K., Park G. Y., Park H. Polypropylene surface with antibacterial property by photografting 1 -vinylimidazole and subsequent chemical modification. Korean Journal of Chemical Engineering. 2018;35: 1748-1755. https://doi.org/10.1007/s11814018-0080-2

19. Camacho-Cruz L. A., Velazco-Medel M. A., Parra-Delgado H., Bucio E. Functionalization of cotton gauzes with poly(N-vinylimidazole) and quaternized poly(N-vinylimidazole) with gamma radiation to produce medical devices with $\mathrm{pH}$-buffering and antimicrobial properties. Cellulose. 2021;28: 32793294. https://doi.org/10.1007/s10570-021-03725-w

20. Dimzon I. K. D., Knepper T. P. Degree of deacetylation of chitosan by infrared spectroscopy and partial least squares. International Journal of Biological Macromolecules, 2015:72: 939-945. https://doi. org/10.1016/j.ijbiomac.2014.09.050

21. Chattopadhyay D. P., Inamdar M. S. Aqueous behavior of chitosan. International Journal of Polymer Science. 2010;2010: 939536. https://doi. org/10.1155/2010/939536

\section{Information about the authors}

Andrey $V$. Sorokin, postgraduate student at the Polymer Science and Colloid Chemistry Department, research assistant at the Department of Biophysics and Biotechnology, Voronezh State University; research assistant at the Laboratory of Metagenomics and Food Biotechnologies, Voronezh State University of Engineering Technologies, Voronezh, Russian Federation; e-mail: andrew.v.sorokin@gmail.com; ORCID ID: https://orcid.org/0000-0001-5268-9557.

Marina G. Kholyavka, DSc in Biology, Associate 
Professor, Professor at the Department of Biophysics and Biotechnology, researcher at the Department of Biochemistry and Cell Physiology, Voronezh State University, Voronezh, Russian Federation; Professor at the Department of Physics; leading researcher at the Core Research Centre "Molecular Structure of Matter”, Sevastopol State University, Sevastopol, Russian Federation; e-mail: holyavka@rambler.ru; ORCID ID: https://orcid.org/0000-0002-1390-4119.
Maria S. Lavlinskaya, PhD in Chemistry, researcher at the Department of Biophysics and Biotechnology, Voronezh State University, Voronezh, Russian Federation; researcher at the Laboratory of Metagenomics and Food Biotechnologies, Voronezh State University of Engineering Technologies, Voronezh, Russian Federation; e-mail: maria. lavlinskaya@gmail.com; ORCID ID: https://orcid. org/0000-0001-9058-027X.

Received September 1, 2021; approved after reviewing October 7, 2021; accepted November 15, 2021; published online December 25, 2021.

Translated by Irina Charychanskaya Edited and proofread by Simon Cox 